\title{
Phentermine and topiramate for the management of obesity: a review
}

This article was published in the following Dove Press journal:

Drug Design, Development and Therapy

4 April 2013

Number of times this article has been viewed

\section{Gina Cosentino' \\ Ariane O Conrad ${ }^{2}$ \\ Gabriel I Uwaifo' \\ 'Section of Endocrinology, Diabetes and Metabolism, Department of \\ Medicine, Louisiana State University Health Sciences Center, New Orleans, LA, USA; ${ }^{2}$ Xavier University of Louisiana College of Pharmacy, New Orleans, LA, USA}

Correspondence: Gabriel I Uwaifo Section of Endocrinology, Diabetes and Metabolism, I542 Tulane Avenue, Department of Medicine, Louisiana State University Health Sciences Center, New Orleans, LA, USA

Tel +I 5045682380

Fax + I 5045682127

Email guwaif@Isuhsc.edu
Abstract: Obesity is now a major public health concern worldwide with increasing prevalence and a growing list of comorbidities and complications. The morbidity, mortality and reduced productivity associated with obesity and its complications result in a major burden to health care costs. Obesity is a complex chronic medical syndrome often with multiple different etiologic factors in individual patients. The long term successful management of obesity remains particularly challenging and invariably requires a multifaceted approach including lifestyle and behavioral modification, increased physical activity, and adjunctive pharmacotherapy. Bariatric surgery remains a last resort though at present it has the best results for achieving sustained robust weight loss. Obesity pharmacotherapy has been very limited in its role for long term obesity management because of the past history of several failed agents as well as the fact that presently available agents are few, and generally utilized as monotherapy. The recent FDA approval of the fixed drug combination of phentermine and extended release topiramate (topiramate-ER) (trade name Qsymia ${ }^{\mathrm{TM}}$ ) marks the first FDA approved combination pharmacotherapeutic agent for obesity since the Phen-Fen combination of the 1990s. This review details the history and clinical trial basis for the use of both phentermine and topiramate in obesity therapeutics as well as the results of clinical trials of their combination for obesity treatment in humans. The initial clinical approval trials offer evidence that this fixed drug combination offers synergistic potential for effective, robust and sustained weight loss with mean weight loss of at least $10 \%$ of baseline achieved and sustained for up to 2 years in over $50 \%$ of subjects treated. It is anticipated that this agent will be the first in a new trend of multi-agent combination therapy for the chronic adjunctive management of obesity.

Keywords: obesity, dysmetabolic syndrome, anorexiants, obesity pharmacotherapy, cardiovascular risk factors, obesity complications

\section{Introduction}

Obesity is a highly prevalent, complex condition that now appears to best fit the chronic disease model well known to apply to other clinical conditions like type 2 diabetes and essential hypertension. ${ }^{1-5}$

There is also evidence that obesity is now becoming a global pandemic that requires the serious attention of clinicians all over the world. ${ }^{1-4}$

Obesity has a complicated, often multifactorial etiology that often makes its effective management difficult. ${ }^{6,7}$ A multifaceted approach that often requires lifestyle modification, dietary alterations, changes in physical activity patterns, as well as pharmacotherapy and/or surgery is often required to achieve sustained weight management in patients with obesity. ${ }^{6,7}$ Obesity effects all age strata from pediatrics through geriatrics ${ }^{8-13}$ and virtually all demographic strata. ${ }^{2,3}$ 
It is now well established that obesity is often complicated by and/or associated with myriad comorbidities and the effective management of obesity is often integral to the effective, sustained management of these comorbidities. ${ }^{6,14,15}$ Effective obesity management thus goes beyond mere improvement in weight but also needs to demonstrate improvement in associated comorbidities and complications of which hypertension, diabetes (or prediabetes with insulin resistance), dyslipidemia, Obstructive sleep apnea syndrome (OSAS) and nonalcoholic steatohepatitis are the most prominent. ${ }^{7,15-17}$

The place of pharmacotherapy in the management of obesity is a long and checkered one. ${ }^{18-22}$ As obesity is a chronic medical problem it is not surprising that the long term success of monotherapeutic pharmaceutical interventions has been somewhat limited. ${ }^{18,19,21,23}$ As found in other chronic disease models, the need for combination phamacotherapy in achieving more robust and sustained weight loss in complicated obesity is now being more appreciated. $6,20,24,25$
Given the established trends and patterns of patient compliance as well as the pressures some medical insurance plans place on patients as regards number of actual prescriptions (not actual medications) that they cover, the place of fixed drug combinations as a management strategy for chronic medical conditions is steadily growing in prominence. ${ }^{26-31}$ The potential increased expense of mounting copays required for individual prescriptions can also be somewhat obviated by such fixed drug combinations. Obesity pharmacotherapy is new to using fixed drug combinations but promises significant potential. ${ }^{32,33}$ While the number of available molecular targets for obesity pharmacotherapy increase as well as the number of potential injectable adjuncts for obesity and its comorbidities, ${ }^{6,17,18,20,34}$ the number of oral agents available for potential fixed drug combinations is significantly more limited. Table 1 details the major oral agent options currently available as well as some that recently became unavailable for clinical use.

Table I Oral agents for potential combination therapy in obesity management

\begin{tabular}{|c|c|c|c|c|c|c|}
\hline Name & $\begin{array}{l}\text { Medication } \\
\text { class }\end{array}$ & $\begin{array}{l}\text { Mode of action for } \\
\text { weight management }\end{array}$ & $\begin{array}{l}\text { Side effects/ } \\
\text { safety profile } \\
\text { concerns }\end{array}$ & FDA approval status & $\begin{array}{l}\text { Combinatorial } \\
\text { trials }\end{array}$ & $\begin{array}{l}\text { Typical } \\
\text { net weight } \\
\text { loss (kg) }\end{array}$ \\
\hline Orlistat & Lipase inhibitor & $\begin{array}{l}\text { Reducing bowel based } \\
\text { fat absorption }\end{array}$ & + & $\begin{array}{l}\text { Approved for obesity } \\
\text { rx, available OTC }\end{array}$ & $\begin{array}{l}\text { With Sibutramine, } \\
\text { metformin and } \\
\text { phentermine }\end{array}$ & $\sim 2.3$ \\
\hline Sibutramine & B-phenethylamine & $\begin{array}{l}\text { Appetite suppressant } \\
\text { and increased energy } \\
\text { expenditure }\end{array}$ & ++++ & $\begin{array}{l}\text { Pulled from the } \\
\text { US market; } 2010\end{array}$ & With orlistat & $\sim 3.5$ \\
\hline Phentermine & Sympathomimetic & Appetite suppressant & ++ & $\begin{array}{l}\text { Approved for short } \\
\text { term obesity rx }\end{array}$ & $\begin{array}{l}\text { With orlistat } \\
\text { and topiramate }\end{array}$ & $\sim 4$ \\
\hline Diethylpropion & Sympathomimetic & Appetite suppressant & ++ & $\begin{array}{l}\text { Approved for short } \\
\text { term obesity rx }\end{array}$ & - & $\sim 3$ \\
\hline Benzphetamine & Sympathomimetic & Appetite suppressant & ++ & $\begin{array}{l}\text { Approved for short } \\
\text { term obesity rx }\end{array}$ & - & $\sim 2.5$ \\
\hline Phendimetrazine & Sympathomimetic & Appetite suppressant & ++ & $\begin{array}{l}\text { Approved for short } \\
\text { term obesity } r x\end{array}$ & - & $\sim 2.5$ \\
\hline Naltrexone & $\begin{array}{l}\text { Partial opioid } \\
\text { antagonist }\end{array}$ & $\begin{array}{l}\text { ? altered satiety } \\
\text { perception }\end{array}$ & ++ & $\begin{array}{l}\text { Approved for } \\
\text { alcohol dependence }\end{array}$ & With bupropion & $\sim 1.6$ \\
\hline Buproprion & Antidepressant & $\begin{array}{l}\text { ? altered satiety } \\
\text { perception }\end{array}$ & ++ & $\begin{array}{l}\text { Approved for } \\
\text { smoking cessation }\end{array}$ & $\begin{array}{l}\text { With naltrexone } \\
\text { and zonisamide }\end{array}$ & $\sim 3.2$ \\
\hline Rimonabant & $\begin{array}{l}\text { Cannabinoid } \\
\text { antagonist }\end{array}$ & $\begin{array}{l}\text { ? altered satiety } \\
\text { perception }\end{array}$ & +++ & $\begin{array}{l}\text { Pulled from the } \\
\text { market in Europe; } \\
2007\end{array}$ & - & $\sim 6.5$ \\
\hline Topiramate & Antiepileptic & $\begin{array}{l}\text { ? appetite suppressant } \\
\text { ? altered satiety } \\
\text { perception }\end{array}$ & +++ & $\begin{array}{l}\text { Approved for epilepsy } \\
\text { and migraine } r x\end{array}$ & $\begin{array}{l}\text { With phentermine } \\
\text { and rimonabant }\end{array}$ & $\sim 2.8$ \\
\hline Zonisamide & Antiepileptic & $\begin{array}{l}\text { ? appetite suppressant } \\
\text { ? altered satiety } \\
\text { perception }\end{array}$ & +++ & $\begin{array}{l}\text { Approved for } \\
\text { epilepsy rx }\end{array}$ & With bupropion & $\sim 7.5$ \\
\hline Metformin & $\begin{array}{l}\text { Biguanide } \\
\text { antidiabetic }\end{array}$ & $\begin{array}{l}\text { Unclear? Mild } \\
\text { anorexiant }\end{array}$ & + & $\begin{array}{l}\text { Approved for diabetes } \\
\text { and PCOS rx }\end{array}$ & $\begin{array}{l}\text { With orlistat } \\
\text { and rimonabant }\end{array}$ & $\sim 2$ \\
\hline Lorcaserin & Sympathomimetic & $\begin{array}{l}\text { Appetite suppressant; } \\
\text { serotonin } 2 c \text { agonist }\end{array}$ & +++ & $\begin{array}{l}\text { Approved for } \\
\text { monotherapy of obesity }\end{array}$ & - & $\sim 3.7$ \\
\hline
\end{tabular}

Abbreviations: OTC, over-the-counter; PCOS, polycystic ovary syndrome. 
A central premise for the role of combination therapy in the management of obesity is the potential of synergism between the component medications resulting in weight loss that exceeds the weight loss associated with the component medications..$^{24,26,33}$ Another important premise underlying development of combination therapy for obesity management is the potential to utilize lower doses of the component medications whilst retaining comparable additive and/or synergistic effect and minimizing adverse reactions.

While the two prime examples of combination pharmacotherapy for obesity are no longer available for clinical prescription because of long term safety concerns, the combinations of ephedrine and caffeine as well as of phentermine and fenfluramine did provide important historical examples of the clinical potential of combination therapy in long term obesity management. ${ }^{35-40}$ Currently there are two fixed drug combination formulations either approved or undergoing review for potential approval for the chronic pharmaceutical adjunctive management of obesity. Orexigen Therapeutics (La Jolla, CA, USA) holds the patent and license for a fixed drug combination of sustained release naltrexone and sustained release bupropion that is in review by the FDA (pending the results of ongoing cardiovascular safety studies) for clinical use in the management of obesity. ${ }^{41-44}$ This combination medication is presently known by the trade name of Contrave ${ }^{\circledR}$.

Vivus (Mountain View, CA, USA) patented and licensed the fixed drug combination of phentermine and an extended release formulation of topiramate which will be discussed in more detail later in this review and was recently FDA approved for marketing under the trade name Qsymia (previously known as Qnexa). ${ }^{45-47}$

\section{Drug overview of phentermine}

Phentermine (Adipex- ${ }^{\circledR}$, Teva Pharmaceuticals, Philadelphia, PA, USA), initially FDA approved in $1959,{ }^{48,49}$ is the most commonly prescribed medication for the management of obesity in the United States. ${ }^{50-52}$ It is known by a host of other names worldwide including Suprenza ${ }^{\mathrm{TM}}$ (Alpex Pharma, SA, Lugano, Switzerland), Ionamin (UCB Inc., Smyrna, GA, USA), Duromine (3M Pharmaceuticals, Thornleigh, NSW, Australia), Obephe, Obermine, Phentrol, Phenterex (Phenterex, Penfield, NY, USA), Phentromin and Obenix among others. It is indicated for the short-term adjunctive therapy in patients with an initial body mass index (BMI) $\geq 30 \mathrm{~kg} / \mathrm{m}^{2}$ or $\geq 27 \mathrm{~kg} / \mathrm{m}^{2}$ with other obesity associated risk factors (eg, controlled hypertension, diabetes, dyslipidemia). ${ }^{53-55}$ This agent is a sympathomimetic amine pharmacologically related to amphetamine which acts centrally as an appetite suppressant. ${ }^{53-55}$ Because of this relationship with amphetamine, it was determined to have the potential for abuse and designated as a Schedule IV controlled substance..$^{53-55}$

Phentermine is administered orally as a tablet or capsule one to two times daily. ${ }^{53-55} \mathrm{It}$ is available as a $37.5 \mathrm{mg}$ tablet and a 15,30 , and $37.5 \mathrm{mg}$ capsule. ${ }^{53-55}$ The recommended dosing schedule is $15-37.5 \mathrm{mg}$ daily administered before breakfast or 1 to 2 hours after breakfast daily. ${ }^{53-55}$ For some patients, it is more beneficial to prescribe one-half tablet two times daily but caution should be exercised when administering this medication too late in the evening due to the risk of insomnia. ${ }^{53-55}$ In general, dosing should be individualized so that the lowest dose may be used while achieving the desired weight loss outcome.

The most common side effects experienced include dry mouth and insomnia. ${ }^{50-52}$ According to the package insert, phentermine therapy is associated with cardiovascular complications including primary pulmonary hypertension $+/$ - regurgitant cardiovascular disease, palpitations, tachycardia, increased blood pressure, and ischemic events. ${ }^{55,56}$ Therefore, it is contraindicated for use in patients with a history of cardiovascular disease, including uncontrolled hypertension. However, data suggest that phentermine may not be associated with serious adverse events and that use may actually cause blood pressure lowering associated with the resultant weight loss. ${ }^{22,50-52,57,58}$ The cardiac side effects noted are consistent with this class of medications even if they haven't been specifically identified with phentermine monotherapy. Other contraindications for phentermine therapy include use with monoamine oxidase inhibitors, hyperthyroidism, glaucoma, agitation states, pregnancy, and use in patients with known history of drug abuse..$^{55}$

The potential for abuse with phentermine is a major concern among providers which may preclude prescribing this agent for weight loss. The validity of this concern has been investigated in a recently published study. ${ }^{50,51}$ The primary goal of this study was to evaluate the addiction potential of long-term phentermine therapy (defined as $>90$ days) through the use of psychometric scales designed to assess for typical withdrawal symptoms. Each of the patients evaluated was being treated with phentermine and stopped therapy on their own. None of these patients exhibited cravings for phentermine or typical withdrawal symptoms that would be expected in a patient abruptly stopping therapy with an amphetamine related medication. Based on this information, it could be concluded that this agent probably has a very low potential for actual physical/physiologic 
dependency. However, this may not necessarily be the case for a patient treated with phentermine for long term therapy ( $>1$ year, for example). Also, this may not be the case for a patient with a history of dependency issues so caution and appropriate clinical judgment is still warranted.

\section{Clinical trials of phentermine use in the pharmacotherapy of obesity}

Most of the Clinical research studies on phentermine use for obesity management were relatively short duration, involving small cohorts and completed between the 1960s and 80s. According to a pooled analysis of several placebo-controlled randomized controlled trials lasting 2 to 24 weeks, patients that were treated with phentermine had a $3.6 \mathrm{~kg}$ greater weight loss when compared to the placebo group. ${ }^{22}$ The authors of this analysis determined that the addition of phentermine to lifestyle modifications did result in a statistically significant increase in weight loss. One of the longest studies conducted using phentermine was published in $1968 .{ }^{57}$ One-hundredeight obese women were randomly assigned to receive placebo, continuous phentermine daily, or intermittent phentermine ( 4 weeks on therapy and 4 weeks off of therapy) for 36 weeks. All of these patients were instructed to follow an $\sim 1000$ calorie/day diet but were not provided any further counseling regarding lifestyle modifications. Sixty-four patients completed the trial with a mean weight loss of 10.5 pounds $(4.8 \mathrm{~kg})$ for the placebo group, 27 pounds $(12.2 \mathrm{~kg})$ for the continuous phentermine group, and 28.7 pounds $(13 \mathrm{~kg})$ for the intermittent phentermine group. These results demonstrated that intermittent therapy may be as effective as daily phentermine treatment. Of note, the patients receiving intermittent therapy experienced some weight regain or lost weight more slowly during the 4 weeks on placebo. Weight loss reccurred when the phentermine was restarted indicating that the drug is really only effective during the time that it is being taken. ${ }^{36,51,54,56,57,59}$

Phentermine has a long history of effectiveness for weight loss, albeit with a clinically modest effect. The clinical response to phentermine as with virtually all obesity pharmaceuticals can be quite variable ranging from very modest to profound ${ }^{35,38,39,60}$ with associated salutary effects on obesity associated comorbidities including blood pressure, glycemic and lipid profiles. A persistent challenge continues to be correctly identifying initially those patients who will respond best to this medication as an adjunctive intervention in their chronic weight management. Also, in spite of the presumed risks, the data shows that it is generally well tolerated with relatively minor symptoms associated with its use even in the longterm. ${ }^{21,35,36,38,39,51,54,55,59}$ Unfortunately, this medication is still only FDA approved for short term use and obesity is a chronic condition requiring long-term management. Because of this, it is not a surprise that phentermine is commonly prescribed clinically for longer than the 12 weeks recommended in its package insert. ${ }^{21,35,36,38,39,51,54,59}$ It is recommended that such patients though be closely monitored for the development of potential side effects (particularly elevated blood pressure and tachyarrhythmias) while on therapy. Patients should also be counseled regarding the appropriate timing of the phentermine dose since the potential for insomnia is greater if the dose is taken too late in the day. Despite some of the potential issues with this medication however, phentermine remains the most commonly prescribed anti-obesity agent in the United States and much of the world and has remained so for several decades.

\section{Drug overview of topiramate}

Topiramate (Topamax ${ }^{\circledR}$, Janssen Pharmaceuticals, Inc, Titusville, NJ, USA) has a long and checkered history in clinical therapeutics. Topiramate is a sulfamate-substituted monosaccharide marketed since 1996, and initially approved by the FDA for management of seizure disorders. It was first investigated as a antidiabetic medication; as a fructose-1,6diphosphate analog (sulfamate-substituted monosaccharide) that inhibits fructose 1,6-bisphosphatase and thus inhibit gluconeogenesis. ${ }^{61-64}$ It was eventually marketed for its $\mathrm{Na}+$ and $\mathrm{Ca} 2+$ channel blocking activity which is typical of antiepileptic drugs. ${ }^{61-64}$ Studies have also shown that topiramate causes a smaller increase in extracellular dopamine rise after administration of nicotine or cocaine in rats, as well as lowering extracellular levels of glutamate and aspartate in seizure-prone rats, perhaps by its inhibition of exocytosis, in a dose-dependent manner. ${ }^{61-64}$ Efficacy in treating migraines was found incidentally during clinical trials for epilepsy and it was subsequently approved for prophylactic treatment and prevention of migraine headaches as well. ${ }^{61-64}$ The likely mechanism for this observed effect is inhibition of 2 subtypes of glutamate receptors as well as voltage-gated $\mathrm{Ca} 2+$ channels, with a small effective range of doses, 50-100 mg/day. ${ }^{61-64}$

As its usefulness in migraine prophylaxis was discovered incidentally, so was topiramate found to have potential as a weight loss medication during its trials as an antiepileptic drug published in 2002 and 2003, and then later was found to have diabetes-fighting qualities independent of the amount of weight that patients lost. ${ }^{61-64}$ This may be in part from sensitization of previously insulin-desensitized adipocytes, skeletal muscle, and pancreatic B-cells. ${ }^{61-64}$

Topiramate was also found to have effects on neuropeptide-Y as well as its Y1 and Y5 receptors, corticotrophin-releasing 
hormone and type-II glucocorticoid receptors in rats in whom its weight loss characteristics were being examined. ${ }^{62,63}$

Table 2 details some of the observed, reported and putative modes of action of topiramate based on in vitro, as well as in vivo animal based trials. The product development profile of topiramate has included forays into its potential as an antidiabetic, and antiepileptic, a neuroprotective agent and a migraine prophylactic amongst others.

Several of the adverse effects of topiramate may be related to its inhibitory effect of carbonic anhydrase. ${ }^{65,66}$ Paresthesias of the distal extremities and periorbitally are a potential side effect as they are with other drugs with carbonic anhydrase inhibiting activity, and may possibly be relieved by potassium supplementation. In addition to paresthesias, the carbonic anhydrase inhibitor activity of topiramate can contribute to a metabolic acidosis and type 3 renal tubular acidosis. ${ }^{62,6466}$ However in the metabolic acidosis, plasma bicarbonate levels are seldom less than $18 \mathrm{mM}$. The acidosis can usually be resolved by reducing the dose of topiramate and administration of sodium bicarbonate if needed. Nephrolithiasis is also more common among patients taking topiramate and the incidence can be decreased with potassium citrate supplementation. ${ }^{62-64}$

Central nervous system side effects including cognitive decline, memory deficits, dizziness, word finding difficulty etc are usually the major consideration and limitation to maximizing the dose of topiramate that patients can tolerate..$^{7,1961-64}$ One study did find that patients were more tolerant of these side effects when rivastigmine, a cholinesterase inhibitor was added to the treatment regimen. ${ }^{6466}$

Oligo- or hypohidrosis which is the decreased ability to cool the body by sweating is thought to also occur due to carbonic anhydrase inhibitory activity or by inhibition of aquaporin 5 in sweat glands. ${ }^{64-66}$

Table 2 Identified and putative modes of action of topiramate peripherally and centrally ${ }^{65,66}$

\begin{tabular}{|c|c|c|}
\hline Receptor/substrate & Activity & $\begin{array}{l}\text { Distribution } \\
\text { of activity }\end{array}$ \\
\hline $\begin{array}{l}\text { I. Gamma aminobutyric acid receptor } \\
(\alpha-\mid \text { subunit })\end{array}$ & Agonist & Central \\
\hline 2. Sodium ion channel ( $\alpha-\mid$ subunit) & Antagonist & $\begin{array}{l}\text { Central and } \\
\text { peripheral }\end{array}$ \\
\hline 3. Carbonic anhydrase 2 and 4 & Inhibitor & Systemic \\
\hline 4. Glutamate ionotropic kainate type I & Antagonist & Central \\
\hline 5. Cytochrome P450 $2 \mathrm{Cl} 9$ & Inhibitor & Systemic \\
\hline 6. Cytochrome P450 3A4 & Inducer & Systemic \\
\hline $\begin{array}{l}\text { 7. Calcium } \alpha-I \text { subtype cellularion } \\
\text { channel }\end{array}$ & Antagonist & $\begin{array}{l}\text { Central and } \\
\text { peripheral }\end{array}$ \\
\hline 8. ATP activated anion channel (CFTR) & Antagonist & ? systemic \\
\hline
\end{tabular}

Abbreviations: ATP, adenosine triphosphate; CFTR, cystic fibrosis transmembrane condulence regulator.
Vision disturbances including diplopia, blurred vision, myopia, as well as the more severe acute myopia and secondary angle-closure glaucoma have been reported. ${ }^{64-66}$ There are other side effects that are included in the package insert and mentioned in associated clinical trial and these tend to be dose-dependent including the neurologic symptoms of dizziness, ataxia, and tremor, the gastrointestinal related symptoms of abdominal pain, constipation, adverse taste and dry mouth and some psychiatric problems such as nervousness, depression, anorexia, agitation, and mood problems. ${ }^{64-69}$

\section{Use in special populations}

Topiramates use in children older than 2-years is wellestablished in the treatment of epilepsy and usually well tolerated, although there is a higher incidence of metabolic acidosis in younger patients. ${ }^{10,64}$ Topiramate has been shown to be teratogenic in animal studies. ${ }^{70}$ In humans there is an increased risk of oral clefts, and because of this the medication has a category $\mathrm{D}$ designation and should absolutely not be used in pregnant women. In addition, use of the medication in women of reproductive age should be done with adequate counseling of the patient and appropriate effective contraception The effects of metabolic acidosis may be more dire in pregnant women and may cause harm to the patient or result in fetal death. ${ }^{70}$ While there is little information detailing the degree of topiramate elaboration in human breast milk of lactating women taking the medication, caution is generally advised as regards continuing or commencing lactation whilst taking the medication as the potential risk to the breast fed infant in such scenarios is unknown.

\section{Clinical trials of topiramate use in the pharmacotherapy of obesity}

Weight loss was noted as a side effect as topiramate was being investigated for other uses such as migraine prevention, seizures and bipolar disorder. In Storey et al's paper from $2001,{ }^{67} 40$ patients with migraine were randomized to placebo or topiramate in a double blind study and titrated up to $200 \mathrm{mg}$ or the largest tolerated dose. They found that topiramate was generally well tolerated and decreased mean migraine activity significantly, but also noted as adverse events weight loss (53\% of the topiramate group versus $29 \%$ of the placebo group) as well as altered taste; dysguesia (37\% of the topiramate group versus $0 \%$ of the placebo group) and anorexia ( $21 \%$ of the topiramate group versus $5 \%$ of the placebo group). ${ }^{67}$ 
In 1999, Chengappa et al added topiramate to the medical treatment of 18 patients with bipolar I and schizoaffective disorder - bipolar type. ${ }^{67,68}$ All of the patients in their study eventually lost weight at an average of $9.4 \mathrm{lbs}(4.08 \mathrm{~kg})$ over the 5 weeks study period. Patients in this study who were noted to have higher BMIs at the study start had slightly more weight loss than their thinner counterparts. ${ }^{67,68}$ They also noted that three of five patients with diabetes achieved "good glycemic control" without altering any of their current diabetes medications.

In 2003, Ben-Menachem et al published the first prospective study of the weight loss effects of topiramate as well as investigating the major predictors of weight loss. ${ }^{71}$ It was a small study -49 patients were enrolled and 38 completed one year of treatment. Topiramate was added to all the patients' current regimen of AEDs and titrated up as side effects allowed. The mean dose was $81 \mathrm{mg} /$ day after 3 months and $129 \mathrm{mg} /$ day after 12 months. They found that obese patients lost a higher percentage of body weight than did their normal or overweight counterparts. They also continued to lose weight at almost the same rate throughout the study when thinner patients' weight loss declined after the first 3 months. Calories consumed were noted to decrease in the beginning of topiramate use, but by 1 year patients were eating almost the same amount of calories as they had in pre-treatment. In general, fat composed a greater portion of the weight loss than lean mass when body composition was measured. Ultimately they found that while caloric intake correlated with weight loss with most patients at the 3 month mark, as the study progressed initial BMI was more strongly correlated with weight loss. ${ }^{71}$

Johnson and Johnson (New Brunswick, NJ, USA) sponsored a series of large randomized, double-blind, placebocontrolled trials that were ultimately cut short (2002) in order for the company to focus on production of a controlled release formulation. All of these trials included in all groups, enrollment in the "Pathways to Change", a standardized behavioral modification and weight management program. ${ }^{61}$ One of these studies by Tonstad et $\mathrm{al}^{61}$ looked at treatment of obese patients (BMI 27-50) with hypertension (stage I-II). 574 patients were initially enrolled, but because of the truncated nature of the study, 158 were analyzed as the modified intent to treat population, 529 were analyzed for safety, and only 118 completed 28 weeks of the originally intended 52-week treatment phase. ${ }^{61}$ They were able to report significant amounts of weight loss (5.9\% in the $96 \mathrm{mg}$ group and $6.5 \%$ in the $192 \mathrm{mg}$ group) as well as significant decreases in diastolic blood pressure. Systolic BP also decreased but not significantly. ${ }^{61}$
A randomized, double-blind, placebo-controlled, doseranging trial was conducted by Bray et al and reported in 2003. ${ }^{69}$ This trial was able to run through the entire planned 6 months and 248 patients of 385 randomized patients completed the trial. Dosing of topiramate was 64, 96, 192, or $384 \mathrm{mg} /$ day. Patients had BMIs of $30-50 \mathrm{~kg} / \mathrm{m}^{2}$. BMIs of 27-30 were also allowed if the patients had well controlled comorbidities of hypertension or hyperlipidemia. Results showed that all the topiramate groups showed an increased amount of weight loss and all were significant when compared to placebo. However, the $384 \mathrm{mg}$ /day group did not show more weight loss than the $192 \mathrm{mg}$ /day group. ${ }^{69}$

Blood pressures were also monitored in this trial at each treatment visit, and significant decreases were found in all treatment groups versus placebo. The greatest change in systolic pressure was in the $192 \mathrm{mg}$ /day group and the greatest change in diastolic pressure was in the $96 \mathrm{mg}$ /day group. The report mentioned four cases of patients who had serious adverse effects that were felt to be related to the topiramate: one case of Nephrolithiasis, one patient who developed elevated liver enzymes, one patient who had a motor vehicle accident with resulting injury (and was probably unrelated to the medication use), and one woman who developed severe hyperchloremic acidosis. In this last case, the woman's bicarbonate rose and chloride level fell to near pre-treatment levels after being off topiramate for 2 weeks.

In response to the paper by Bray et al, ${ }^{69}$ Wilding et al ${ }^{72}$ began a randomized double-blind placebo-controlled trial that was planned to run for 2 years and would document safety in an obese population at topiramate doses of 96,192 , or $256 \mathrm{mg} /$ day. This study too was cut short to one year when Johnson and Johnson discontinued trials in order to pursue development of a timed-release version. This was one of the larger studies with a safety population of 1282 patients and a modified intent to treat population of 854. Again, all of the treatment groups showed significant weight loss compared with placebo as well as significant increase in those who lost $>5 \%$ and $>10 \%$ of their baseline body weight. ${ }^{72}$ Weight loss was noted to continue throughout the entire year of the study. This study supported the findings from the earlier Bray et $a 1^{69}$ study, including that there was not a great deal of weight loss seen by increasing the dose of topiramate to greater than $192 \mathrm{mg} /$ day. ${ }^{72}$ Impaired glucose tolerance was normal by 60 weeks in $50 \%$ in the treated group versus $40 \%$ in the placebo group. There was no significant improvement in blood lipids. ${ }^{72,73}$

In the safety analysis of the Wilding et $\mathrm{al}^{72}$ study cohort, $6 \%$ of patients in the placebo group compared to 15,25 , 
and $24 \%$ in the $96-, 192-$, and $256 \mathrm{mg}$ /day groups required dose reductions in order to cope with adverse events of the drug/placebo. Nine percent of the placebo group compared to $11 \%$ of the active treatment group reported serious adverse events including four patients with suicidal ideation and two self-reported suicide attempts in the treatment arm. Five of the six cases resolved with cessation of topiramate and one patient continued to have depressed mood after stopping the drug.

\section{Overview of combination therapy of phentermine and topiramate}

Vivus (Mountain View, CA, USA) have spearheaded the clinical development of a combination of phentermine and topiramate for the clinical management of obesity. ${ }^{74-79}$ Initially called Qnexa this proprietary fixed drug combination which obtained FDA approval for use in the clinical management of obesity in July 2012 now bears the proprietary name Qsymia. ${ }^{74-79}$ This preparation is a once daily combination of extended release topiramate (topiramate ER) and phentermine. Unlike regular topiramate which has a half-life of 19-23 hours, the extended release form has a half-life of greater than 24 hours with a significantly slower onset of action and longer time to establishment of steady state compared to regular topiramate. ${ }^{70,80}$ This formulation is suggested to thus have a longer duration of action and better tolerability profile compared to regular topiramate. The combination of topiramate and phentermine has been approved by the FDA for use along with reduced dietary caloric intake for the management of obese subjects or overweight subjects with at least one weight related comorbidity. ${ }^{74-79}$ At present there are four different fixed drug combinations of this agent; a starting dose of 3.75/23 mg (phentermine/topiramate ER), a recommended dose of $7.5 / 46 \mathrm{mg}$, a titration dose of $11.25 / 69 \mathrm{mg}$ and a maximum dose of 15/92 mg. ${ }^{76,80}$ The product has been approved with a Risk Evaluation and Mitigation Strategy (REMS) initiative aimed at educating prescribers, and female patients particularly, regarding the potential risks of development of orofacial clefts if patient are exposed to the medication during the first trimester of pregnancy. ${ }^{76,80}$ This risk is entirely due to the topiramate component of the combination and so the medication is absolutely contraindicated for use in pregnancy. ${ }^{76,80}$ While already approved for use by the FDA within the United States for adjunctive management of obesity, its approval for use in the European union and Asia is still pending. Furthermore there remains an intent to perform further studies to obtain additional therapeutic indications for its use as an adjunctive antidiabetic, for management of obstructive sleep apnea and for potential use in pediatric obesity. ${ }^{74-77,80}$ Other studies still in the early stages of development and execution include studies of the medications use in various stages of renal compromise and a definitive events powered clinical trial to assess its impact on the prospective development of major adverse cardiovascular disease among those with confirmed baseline atherosclerotic vascular disease (that is a secondary cardiovascular prevention trial). ${ }^{74-77,80}$

Preliminary phase 1 trials using these formulations in small cohorts of subjects with varying degrees of renal and hepatic compromise helped establish the now recommended dosing schedule. ${ }^{80}$

\section{Clinical trials of the combination of phentermine and topiramate in the pharmacotherapy of obesity}

There are five major clinical trials of note that were instrumental in the ultimate FDA approval of Qsymia; EQUIP, EQUATE, CONQUER, SEQUEL and FORTRESS (Fetal Outcome Retrospective TopiRamate ExpoSure Study). ${ }^{45-47,81-83}$. The following paragraphs discuss the major findings from these studies while Table 3 details the major features of these studies.

EQUIP; This was a randomized, double blind placebo controlled Phase III trial designed to evaluate the effect of Qsymia on weight loss in conjunction with recommended $500 \mathrm{kcal} /$ day deficit in obese subjects with BMIs of $\geq 35$ over $\mathrm{a} \sim 1$ year period..$^{47}$ The trial involved two treatment arms of $3.75 / 23 \mathrm{mg}$ and $15 / 92 \mathrm{mg}$ dosing in addition to a placebo arm and lasted for 56 weeks. The study primary end points were $\%$ weight loss from baseline and $\%$ of study participants achieving at least 5\% weight loss from baseline. ${ }^{47}$ The intent to treat, last observation carried forward analysis showed that for the $15 / 92 \mathrm{mg}$ dose, $67 \%$ of study participants achieved at least a $5 \%$ weight loss while $47 \%$ achieved at least a $10 \%$ weight loss from baseline (compared to $45 \%$ and $19 \%$ respectively in the $3.75 / 23 \mathrm{mg}$ dosage group). These findings became even more impressive with "completers only" analyses. The mean weight loss for the maximum dose in the cohort was $\sim 14.4 \%$ (compared to $\sim 6.5 \%$ in the $3.75 / 23 \mathrm{mg}$ dosage group). Further analyses of other cardiometabolic surrogates including blood pressure, lipid profiles and fasting glucose showed no statistically significant benefits though the trends observed suggested minimal improvements. ${ }^{47}$ Beyond weight loss however the treatment groups of the cohort also demonstrated significant improvements in waist circumference measures suggesting possible diminution in visceral fat depots. 
Table 3 Clinical approval trials for Qsymia

\begin{tabular}{|c|c|c|c|c|c|c|c|}
\hline $\begin{array}{l}\text { Trial } \\
\text { name }\end{array}$ & $\begin{array}{l}\text { Number } \\
\text { of patients }\end{array}$ & $\begin{array}{l}\text { Study } \\
\text { population }\end{array}$ & $\begin{array}{l}\text { Medication } \\
\text { treatment arms }\end{array}$ & $\begin{array}{l}\text { Study } \\
\text { duration }\end{array}$ & $\begin{array}{l}\text { Mean \% weight } \\
\text { loss from baseline } \\
\text { (in maximum } \\
\text { dose group) }\end{array}$ & $\begin{array}{l}\% \text { of subjects with } \\
\text { at least } 5 \% \text { weight } \\
\text { loss (in maximum } \\
\text { dose group) }\end{array}$ & $\begin{array}{l}\% \text { of subjects with } \\
\text { at least } 10 \% \text { weight } \\
\text { loss (in maximum } \\
\text { dose group) }\end{array}$ \\
\hline EQUIP47 & 1267 & $\mathrm{BMI} \geq 35$ & $\begin{array}{l}3.75 / 23 \mathrm{mg} \text { and } \\
15 / 92 \mathrm{mg}\end{array}$ & 56 weeks & 14.4 & 67 & 47 \\
\hline EQUATEE & 756 & $\begin{array}{l}\text { Non diabetic, } \\
\text { BMI } \geq 35\end{array}$ & $\begin{array}{l}7.5 / 46 \mathrm{mg} \mathrm{I} / 5 / 96 \mathrm{mg} \\
\text { and } 7.5 \text { and } 15 \mathrm{mg} \\
\text { alone of phentermine } \\
\text { as well as } 46 \text { and } \\
92 \mathrm{mg} \text { alone of } \\
\text { topiramate }\end{array}$ & 28 weeks & 9.2 & & 40.8 \\
\hline CONQUER $^{45}$ & 2487 & $\begin{array}{l}\mathrm{BMI} \geq 27 \text { and } \\
\leq 45 \pm \text { clinical } \\
\text { comorbidities }\end{array}$ & $\begin{array}{l}7.5 / 46 \mathrm{mg} \text { and } \\
15 / 92 \mathrm{mg}\end{array}$ & 56 weeks & 12.4 & 70 & 48 \\
\hline SEQUEL ${ }^{46}$ & 676 & $\begin{array}{l}\text { Same as } \\
\text { CONQUER }\end{array}$ & Same as CONQUER & 2 yrs & 10.5 & 79.3 & 53.9 \\
\hline FORTRESS ${ }^{83, *}$ & $*$ & $*$ & $*$ & $*$ & $*$ & $*$ & $*$ \\
\hline
\end{tabular}

Note: *Retrospective case control comparison study of pregnancy related teratogenic risk potential.

CONQUER; This was another randomized double blind placebo controlled Phase III trial designed to evaluate degree of weight loss over a 56 week period in subjects who were either obese at baseline or overweight with significant associated comorbidities and a recommended $500 \mathrm{kcal} /$ day deficit. ${ }^{45}$ The treatment arms involved in the trial included a $7.5 / 46$ and a $15 / 92 \mathrm{mg}$ arm. The primary end points of the study were similar to those of the EQUIP trial and the intent to treat, last observation carried forward findings showed that while the $7.5 / 46 \mathrm{mg}$ dose group was associated with $62 \%$ of subjects achieving at least $5 \%$ weight loss from baseline and $37 \%$ achieving at least $10 \%$ weight loss, the $15 / 92 \mathrm{mg}$ dose was associated with $70 \%$ of participants achieving at least $5 \%$ weight loss from baseline while $48 \%$ achieved at least $10 \%$ weight loss. The findings again significantly improved with "completers only" analyses. The mean weight loss for the maximum dose group in the cohort was $\sim 12.4 \%$ and $\sim 9.6 \%$ for the 7.5/46 mg dose arm. ${ }^{45}$ As with EQUIP, none of the cardiometabolic surrogates measured other than waist circumference showed statistically significant improvements though the observed trends suggested minimal benefits.

EQUATE; This was another randomized double blind placebo controlled Phase III trial over a 28 week period which confirmed the superiority of the phentermine/topiramate combination to the individual components alone. ${ }^{81,82}$ As with other clinical trials subjects were recommended to implement a $500 \mathrm{kcal} /$ day deficit diet during the study period and the treatment arms were $7.5 / 46 \mathrm{mg}$ and $15 / 92 \mathrm{mg}$ of the combination as well as $7.5 \mathrm{mg}$ and $15 \mathrm{mg}$ alone or phentermine, 46 and $92 \mathrm{mg}$ alone of topiramate and a placebo arm. The mean weight loss achieved for the maximum dose combination was $\sim 9.21 \%$ compared to $6.06 \%$ in the max dose phentermine alone and $6.44 \%$ in the max dose topiramate alone groups and these findings were statistically significant. The $7.5 / 46 \mathrm{mg}$ group was associated with $\sim 8.46 \%$ weight loss from baseline. In addition, $\sim 38.8 \%$ of the $7.5 / 46 \mathrm{mg}$ group and $\sim 40.8 \%$ of subjects in the maximum dose combination group achieved at least $10 \%$ weight loss. An additional benefit of improvement in glycemic profiles was also reported.

SEQUEL; This was the 2 year extension study of the study completers from the CONQUER study cohort. The study design was essentially similar as were the treatment arms and this study demonstrated the durability of the findings from the CONQUER study over a 2 year period. ${ }^{46}$ The mean weight loss observed over the 2 year period in the maximum dose group was $\sim 10.5 \%$ and $\sim 9.3 \%$ in the $7.5 / 46 \mathrm{mg}$ group while the $\%$ of the cohort able to achieve at least $5 \%$ weight loss was $79.3 \%$ in the maximum dose group and $75.2 \%$ in the 7.5/46 mg group. Those percentage of patients achieving at least $10 \%$ weight loss in the maximum dose group was $53.9 \%$ and $50.3 \%$ in the $7.5 / 46 \mathrm{mg}$ group. ${ }^{46}$ All these were statistically significantly better than the placebo treatment group. In addition this clinical trial demonstrated a $76 \%$ reduction in new onset type 2 diabetes in the maximum dose treatment group.

FORTRESS; This was a retrospective study to evaluate and quantify the potential risk of teratogenicity associated with exposure to the phentermine/topiramate combination during pregnancy in humans. ${ }^{83}$ To estimate the relative 


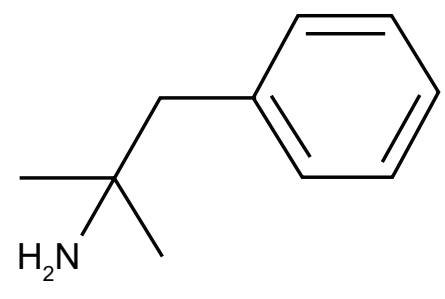

Figure I Phentermine.

Note: $\mathrm{C}_{10} \mathrm{H}_{15} \mathrm{~N}$ formal chemical name (IUPAC): 2-methyl-I-phenylpropan-2-amine.

risk for orofacial clefts and other congenital malformations a comparison was done between the prevalence rates of such findings in women who were exposed to topiramate during pregnancy but who discontinued its use (previously exposed cohort) to a second cohort of pregnant women with similar clinical profiles but no topiramate exposure. Exposed women had nearly a $2 \mathrm{x}$ greater risk for having children with oral clefts with estimated prevalence rates amongst those actively using topiramate of $\sim 0.29 \%$, compared to $\sim 0.16 \%$ among previously exposed women and prevalence ratio of 1.88 (0.7-5.03 95\% confidence interval) between continuous pregnancy exposed to previously exposed groups. The women with similar clinical profiles who, however had no history of topiramate exposure had oral cleft prevalence rates of $\sim 0.07 \%$.

The current dosing schedule for Qsymia included in the product insert ${ }^{80}$ recommends starting with two prescriptions; a 14 day prescription of the $3.75 / 23 \mathrm{mg}$ dose for initiation followed by the maintenance dose of 7.5/46 mg daily with a recommended follow up in 2-8 weeks. After 12 weeks on the maintenance dose based on clinical response a decision can be made as to the need for further dose titration. If at this time less than $3 \%$ weight loss from baseline is achieved, dose escalation is recommended. The dose escalation is again suggested to be a two prescription process with a 14 day prescription of the titration dose of $11.25 / 69 \mathrm{mg}$ followed by the maximum dose of $15 / 92 \mathrm{mg}$ to be continued thereafter

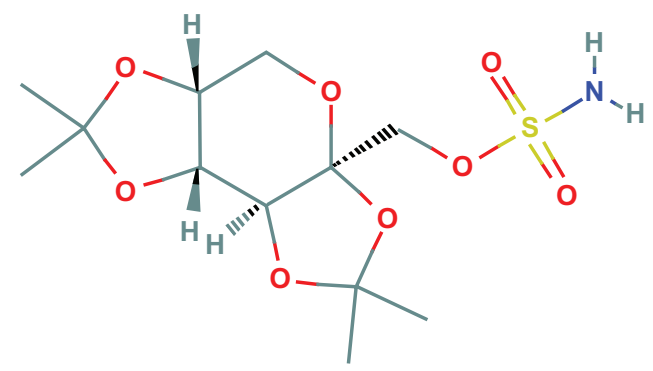

Figure 2 Topiramate.

Note: $\mathrm{C}_{12} \mathrm{H}_{21} \mathrm{NO}_{8} \mathrm{~S}$, formal chemical name (IUPAC): [(3aS,5aR,8aR,8bS)-2,2,7,7tetramethyl-5,5a,8a,8b-tetrahydrodi[ 1,3$]$ dioxolo[4,5-a:5', $\left.3^{\prime}-d\right]$ pyran-3a-yl] methyl sulfamate. for at least 12 weeks. It is suggested that if after 12 weeks of therapy at the maximal dose the weight loss achieved remains less than $5 \%$ of baseline the medication should be discontinued. The stepwise approach to dosing and dose escalation is designed to optimize clinical response while keeping adverse events to the minimum.

The observed side effects from the various certification clinical trials of Qsymia are as would be anticipated based on the individual component medications in the combination. ${ }^{45,47,81-83}$ While the list of potential side effects associated with use of the combination medication is extensive as indicated within the product insert, the most common and important side effects observed (seen in $\geq 5 \%$ of study participants who took the medication and observed at least $1.5 \times$ more than in the placebo treatment arms) were paraesthesiae, dizziness, dysguesia, insomnia, constipation and dry mouth. ${ }^{45-47,81-83}$ Generally the adverse reactions observed were dose related, and were usually observed soon after initiation of therapy and/or dose escalation and were mild to moderate in severity. The majority of them resolved spontaneously without resolution and did not spur stopping the medication. Every potential side effect identified with the individual component medications have been described and noted with the combination preparation and special attention needs to be paid to potential teratogenicity, potential for acute closed angle glaucoma and myriad neuropsychiatric symptomatology including mood disorders and suicidal ideations. ${ }^{4-47,81-83}$ Of note, the adverse reactions noted in the certification trials that had prevalence rates of $>1 \%$ prevalence and were associated with discontinuation of the medication were visual blurring, headaches, irritability, dizziness, paraesthesiae, insomnia, depression and anxiety. ${ }^{45-47,81-83}$

\section{Conclusion}

Overall the clinical results of the trials thus far completed for the fixed drug combination of phentermine and topiramate-ER give reason for measured optimism. The degree of weight loss achieved, the percentage of subjects overall achieving this degree of weight loss and it robustness based on the thus far 2 year follow up data suggest that this combination therapy has an important place to occupy in the armamentarium for chronic obesity management.

Beyond the significant improvement in weight, the findings from various trials of associated improvements in relevant surrogates such as blood pressure, glycemic control and burden as well as waist circumference specifically suggest the potential added utility of the agent in cardiovascular risk modification. The results of planned 
clinical trials to investigate the effect of the combination on actual atherosclerotic vascular event risks is anticipated as are the results of other planned clinical trials in special populations such as pediatrics as well as for other distinct clinical end points such as obstructive sleep apnea.

The recent experiences with some antidiabetic and antilipidemic agents have made it important to proactively establish the cardiovascular safety on medications used in clinical states associated with insulin resistance and the dysmetabolic syndrome such as type 2 diabetes and complicated obesity. Evidence from clinical trial results of rosiglitazone, torcetrapib and the glitizars have shown that improvements in cardiovascular surrogate measures may not necessarily equate to reduction in actual events hence the importance of awaiting the results of the planned vascular event trials. $^{84-86}$

It is also important to note that the clinical certification trials of this agent all utilized a rather modest calorie deficit plan whose actual veracity was not robustly investigated. It is conceivable that in the setting of more robust multidisciplinary clinic settings where closer attention is paid to appropriate calorie deficit plans, behavioral modifications and increased physical activity with added formal exercise sessions, the observed clinical benefits may be significantly greater.

While still very early in the clinical history of the product, the side effect profile noted in the certification clinical trials is tolerable and consistent with expectations from the individual component medications. The most commonly noted side effects associated with Qsymia use and which occurred in $\sim 5 \%$ of the study population were generally relatively minor and included paraesthesiae, dizziness, insomnia, constipation, dysguesia and dry mouth. Of these, only paraesthesiae, insomnia and dizziness along with the less common headaches and neuropsychiatric side effects were associated with treatment discontinuation. Careful attention to education of caregivers prescribing this medication regarding potential side effects and contraindications to its use will play a huge role in preventing mishaps akin to some witnessed with other anti-obesity agents in the past. Close surveillance and phase 4 trial data needs careful scrutiny to ensure ongoing safety of use.

The importance of the fixed drug combination of this preparation as regards improved patient compliance, reduced problems with medical insurance plans that numerate number of prescriptions available for coverage and the unique extended release form of topiramate not otherwise available for clinical management of obesity also add to the unique profile.
The success of the phentermine topiramate-ER combination in the clinical therapeutics of obesity could however extend beyond all the aforementioned. It could be a Rubicon event as it would hopefully usher in a new era in obesity pharmacotherapy that emphasizes combination therapy to enhance synergism, improve efficacy, duration of action and yet simultaneously reduce overall side effects. The fact that another fixed drug combination agent; naltrexone sustained release and bupropion sustained release; trade name Contrave is currently undergoing FDA review for use in obesity management (possible approval pending the results of ongoing cardiovascular safety trials) is encouraging and indicative of this evolving trend.

\section{Disclosure}

Author GIU has served as a speaker for Vivus Pharmaceuticals (Mountain View, CA, USA) in the past for clinical lectures to clinical practitioners on the use of Qsymia in obesity therapeutics. The other authors report no conflicts of interest in this work.

\section{References}

1. Ahluwalia IB, Mack KA, Mokdad A. Report from the CDC. Changes in selected chronic disease-related risks and health conditions for nonpregnant women 18-44 years old BRFSS. J Womens Health (Larchmt). Jun 2005;14(5):382-386.

2. Ford ES, MokdadAH, Giles WH, Galuska DA, Serdula MK. Geographic variation in the prevalence of obesity, diabetes, and obesity-related behaviors. Obes Res. Jan 2005;13(1):118-122.

3. Ford ES, MokdadAH. Epidemiology of obesity in the Western Hemisphere. J Clin Endocrinol Metab. Nov 2008;93(11 Suppl 1):S1-S8.

4. Ford ES, Zhao G, Li C, Pearson WS, Mokdad AH. Trends in obesity and abdominal obesity among hypertensive and nonhypertensive adults in the United States. Am J Hypertens. Oct 2008;21(10):1124-1128.

5. Thorpe KE, Philyaw M. The medicalization of chronic disease and costs. Annu Rev Public Health. Apr 2012;33:409-423.

6. Khan A, Raza S, Khan Y, et al. Current updates in the medical management of obesity. Recent Pat Endocr Metab Immune Drug Discov. May 2012;6(2):117-128.

7. Plourde G, Prud'homme D. Managing obesity in adults in primary care. Cmaj. June 12, 2012;184(9):1039-1044.

8. Robinson GA, Geier M, Rizzolo D, Sedrak M. Childhood obesity: complications, prevention strategies, treatment. Jaapa. Dec 2011; 24(12):58-63.

9. 17 Lakshman R, Elks CE, Ong KK. Childhood obesity. Circulation. October 2, 2012;126(14):1770-1779.

10. Holterman MJ, Le Holterman AX, Browne AF. Pediatric obesity. Surg Clin North Am. Jun 2012;92(3):559-582, viii.

11. Li Z, Heber D. Sarcopenic obesity in the elderly and strategies for weight management. Nutr Rev. Jan 2012;70(1):57-64.

12. Donini LM, Savina C, Gennaro E, et al. A systematic review of the literature concerning the relationship between obesity and mortality in the elderly. J Nutr Health Aging. Jan 2012;16(1):89-98.

13. Mathus-Vliegen EM. Prevalence, pathophysiology, health consequences and treatment options of obesity in the elderly: a guideline. Obes Facts. 2012;5(3):460-483.

14. Witkamp RF. Current and future drug targets in weight management. Pharm Res. Aug 2011;28(8):1792-1818. 
15. Shekelle PG, Morton SC, Maglione M, et al. Pharmacological and surgical treatment of obesity. Evid Rep Technol Assess (Summ). Jul 2004; 103:1-6.

16. Norris SL, Zhang X, Avenell A, Gregg E, Schmid CH, Lau J. Pharmacotherapy for weight loss in adults with type 2 diabetes mellitus. Cochrane Database Syst Rev. 2005;1:CD004096.

17. Chugh PK, Sharma S. Recent advances in the pathophysiology and pharmacological treatment of obesity. J Clin Pharm Ther. Oct 2012;37(5):525-535.

18. Ioannides-Demos LL, Piccenna L, McNeil JJ. Pharmacotherapies for obesity: past, current, and future therapies. J Obes. 2011;2011: 179674.

19. Derosa G, Maffioli P. Anti-obesity drugs: a review about their effects and their safety. Expert Opin Drug Saf. May 2012;11(3): 459-471.

20. Kushner RF, Manzano H. Obesity pharmacology: past, present, and future. Curr Opin Gastroenterol. Mar 2002;18(2):213-220.

21. Ioannides-Demos LL, Proietto J, McNeil JJ. Pharmacotherapy for obesity. Drugs. 2005;65(10):1391-1418.

22. Li Z, Maglione M, Tu W, et al. Meta-analysis: pharmacologic treatment of obesity. Ann Intern Med. April 5, 2005;142(7):532-546.

23. Halford JC, Boyland EJ, Blundell JE, Kirkham TC, Harrold JA. Pharmacological management of appetite expression in obesity. Nat Rev Endocrinol. May 2010;6(5):255-269.

24. Greenway FL, Bray GA. Combination drugs for treating obesity. Curr Diab Rep. Apr 2010;10(2):108-115.

25. Johnson AM. Two new drugs approved for obesity. $S \mathrm{D}$ Med. Sep 2012;65(9):356-357.

26. Taylor AA, Ragbir S. Three in one: safety, efficacy, and patient acceptability of triple fixed-dose combination medicine in the management of hypertension. Patient Prefer Adherence. 2012;6:555-563.

27. Taddei S. Fixed-dose combination therapy in hypertension: pros. High Blood Press Cardiovasc Prev. June 1, 2012;19(2):55-57.

28. Han S, Iglay K, Davies MJ, Zhang Q, Radican L. Glycemic effectiveness and medication adherence with fixed-dose combination or coadministered dual therapy of antihyperglycemic regimens: a meta-analysis. Curr Med Res Opin. Jun 2012;28(6):969-977.

29. Garcia-Donaire JA, Ruilope LM. 'Multiple action fixed combination. Present or future?' Fundam Clin Pharmacol. Feb 24(1):37-42.

30. Gerbino PP, Shoheiber O. Adherence patterns among patients treated with fixed-dose combination versus separate antihypertensive agents. Am J Health Syst Pharm. Jun 2007;64(12):1279-1283.

31. Bangalore S, Shahane A, Parkar S, Messerli FH. Compliance and fixed-dose combination therapy. Curr Hypertens Rep. Jun 2007;9(3): 184-189.

32. Sanz G, Fuster V. Polypill and global cardiovascular health strategies. Semin Thorac Cardiovasc Surg. Spring 2011;23(1):24-29.

33. Garcia-Donaire JA, Ruilope LM. 'Multiple action fixed combination Present or future?' Fundam Clin Pharmacol. Feb 2010;24(1):37-42.

34. Klonoff DC, Greenway F. Drugs in the pipeline for the obesity market J Diabetes Sci Technol. Sep 2008;2(5):913-918.

35. Atkinson RL, Blank RC, Schumacher D, Dhurandhar NV, Ritch DL. Long-term drug treatment of obesity in a private practice setting. Obes Res. Nov 1997;5(6):578-586.

36. Spitz AF, Schumacher D, Blank RC, Dhurandhar NV, Atkinson RL. Long-term pharmacologic treatment of morbid obesity in a community practice. Endocr Pract. Sep-Oct 1997;3(5):269-275.

37. Astrup A, Breum L, Toubro S, Hein P, Quaade F. The effect and safety of an ephedrine/caffeine compound compared to ephedrine, caffeine and placebo in obese subjects on an energy restricted diet. A double blind trial. Int J Obes Relat Metab Disord. Apr 1992;16(4): 269-277.

38. Weintraub M, Sundaresan PR, Schuster B, et al. Long-term weight control study. II (weeks 34 to 104). An open-label study of continuous fenfluramine plus phentermine versus targeted intermittent medication as adjuncts to behavior modification, caloric restriction, and exercise. Clin Pharmacol Ther. May 1992;51(5):595-601.
39. Weintraub M, Sundaresan PR, Madan M, et al. Long-term weight control study. I (weeks 0 to 34). The enhancement of behavior modification, caloric restriction, and exercise by fenfluramine plus phentermine versus placebo. Clin Pharmacol Ther. May 1992;51(5):586-594.

40. Astrup A, Toubro S, Cannon S, Hein P, Madsen J. Thermogenic synergism between ephedrine and caffeine in healthy volunteers: a double-blind, placebo-controlled study. Metabolism. Mar 1991;40(3): 323-329.

41. Mercer SL. ACS Chemical Neuroscience Molecule Spotlight on Contrave. ACS Chem Neurosci. September 21, 2011;2(9):484-486.

42. Ornellas T, Chavez B. Naltrexone SR/bupropion SR (contrave): a new approach to weight loss in obese adults. $P$ T. May 2011;36(5): 255-262.

43. Greenway FL, Dunayevich E, Tollefson G, et al. Comparison of combined bupropion and naltrexone therapy for obesity with monotherapy and placebo. J Clin Endocrinol Metab. Dec 2009;94(12):4898-4906.

44. Greenway FL, Whitehouse MJ, Guttadauria M, et al. Rational design of a combination medication for the treatment of obesity. Obesity (Silver Spring). Jan 2009;17(1):30-39.

45. Gadde KM, Allison DB, Ryan DH, et al. Effects of low-dose, controlledrelease, phentermine plus topiramate combination on weight and associated comorbidities in overweight and obese adults (CONQUER): a randomised, placebo-controlled, phase 3 trial. Lancet. April 16, 2011;377(9774):1341-1352.

46. Garvey WT, Ryan DH, Look M, et al. Two-year sustained weight loss and metabolic benefits with controlled-release phentermine/topiramate in obese and overweight adults (SEQUEL): a randomized, placebocontrolled, phase 3 extension study. Am J Clin Nutr. Feb 2012;95(2): 297-308.

47. Allison DB, Gadde KM, Garvey WT, et al. Controlled-release phentermine/topiramate in severely obese adults: a randomized controlled trial (EQUIP). Obesity (Silver Spring). Feb 2012;20(2):330-342.

48. Colman E. Anorectics on trial: a half century of federal regulation of prescription appetite suppressants. Ann Intern Med. September 6, 2005;143(5):380-385

49. Colman E, Golden J, Roberts M, Egan A, Weaver J, Rosebraugh C. The FDA's assessment of two drugs for chronic weight management. N Engl J Med. October 25, 2012;367(17):1577-1579.

50. Hendricks EJ, Greenway FL. A study of abrupt phentermine cessation in patients in a weight management program. Am J Ther. Jul 2011; 18(4):292-299.

51. Hendricks EJ, Rothman RB, Greenway FL. How physician obesity specialists use drugs to treat obesity. Obesity (Silver Spring). Sep 2009;17(9):1730-1735.

52. Hendricks EJ, Greenway FL, Westman EC, Gupta AK. Blood pressure and heart rate effects, weight loss and maintenance during long-term phentermine pharmacotherapy for obesity. Obesity (Silver Spring). Dec 2011;19(12):2351-2360.

53. Lexicomp. http://online.lexi.com.ezproxy.xula.edu/lco/action/home Lexicomp Online Web Site. Accessed Nov 2012.

54. Bray GA. Drug insight: appetite suppressants. Nat Clin Pract Gastroenterol Hepatol. Feb 2005;2(2):89-95.

55. Adipex- $\mathrm{P}^{\circledR}$ [package insert]. Sellersville, PA: Teva Pharmaceuticals, USA; 2012.

56. Phentermine: an appetite-suppressant amphetamine classified as a narcotic in France. Is a combination with topiramate on the horizon? Prescrire Int. Sep 21(130):209.

57. Munro JF, MacCuish AC, Wilson EM, Duncan LJ. Comparison of continuous and intermittent anorectic therapy in obesity. $\mathrm{Br} \mathrm{Med} J$. February 10, 1968;1(5588):352-354.

58. Rothman RB, Hendricks EJ. Phentermine cardiovascular safety. Am J Emerg Med. Oct 2009;27(8):1010-1013.

59. Makoundou V, Golay A. Drug control of appetite. Rev Med Suisse. January 12, 2011;7(277):57-60.

60. Uwaifo GI, Melcescu E, McDonald A, Koch CA. A case of profound weight loss secondary to use of phentermine. J Miss State Med Assoc. Dec 2009;50(12):407-415. 
61. Tonstad S, Tykarski A, Weissgarten J, et al. Efficacy and safety of topiramate in the treatment of obese subjects with essential hypertension. Am J Cardiol. July 15, 2005;96(2):243-251.

62. Shank RP, Gardocki JF, Vaught JL, et al. Topiramate: preclinical evaluation of structurally novel anticonvulsant. Epilepsia. Mar-Apr 1994; 35(2):450-460.

63. Shank RP, Gardocki JF, Streeter AJ, Maryanoff BE. An overview of the preclinical aspects of topiramate: pharmacology, pharmacokinetics, and mechanism of action. Epilepsia. 2000;41 Suppl 1:S3-S9.

64. Shank RP, Maryanoff BE. Molecular pharmacodynamics, clinical therapeutics, and pharmacokinetics of topiramate. CNS Neurosci Ther. Summer 2008;14(2):120-142.

65. NCBI. Topiramate; Compound summary CID 5284627. Pub Chem compound [website]. Accessed Dec 2012.

66. NCBI. Topamax (TN)-Substance summary SID 7847603 [Website]. Accessed Dec 2012.

67. Storey JR, Calder CS, Hart DE, Potter DL. Topiramate in migraine prevention: a double-blind, placebo-controlled study. Headache. Nov-Dec 2001;41(10):968-975.

68. Chengappa KN, Rathore D, Levine J, et al. Topiramate as add-on treatment for patients with bipolar mania. Bipolar Disord. Sep 1999;1(1):42-53.

69. Bray GA, Hollander P, Klein S, et al. A 6-month randomized, placebocontrolled, dose-ranging trial of topiramate for weight loss in obesity. Obes Res. Jun 2003;11(6):722-733.

70. Lexicomp. Topiramate; Drug information. Uptodate ${ }^{\circledR}$. Available at: http://www.uptodate.com. Accessed Dec 2012.

71. Ben-Menachem E, Axelsen M, Johanson EH, Stagge A, Smith U. Predictors of weight loss in adults with topiramate-treated epilepsy. Obes Res. Apr 2003;11(4):556-562.

72. Wilding J, Van Gaal L, Rissanen A, Vercruysse F, Fitchet M. A randomized double-blind placebo-controlled study of the long-term efficacy and safety of topiramate in the treatment of obese subjects. Int J Obes Relat Metab Disord. Nov 2004;28(11):1399-1410.

73. Astrup A, Toubro S. Topiramate: a new potential pharmacological treatment for obesity. Obes Res. Dec 2004;12 Suppl:167S-173S.

74. Bays HE, Gadde KM. Phentermine/topiramate for weight reduction and treatment of adverse metabolic consequences in obesity. Drugs Today (Barc). Dec 2011;47(12):903-914.
75. Bays H. Phentermine, topiramate and their combination for the treatment of adiposopathy ('sick fat') and metabolic disease. Expert Rev Cardiovasc Ther. Dec 8(12):1777-1801.

76. Cameron F, Whiteside G, McKeage K. Phentermine and topiramate extended release (qsymia): first global approval. Drugs. October 22, 2012;72(15):2033-2042.

77. Malgarini RB, Pimpinella G. Phentermine plus topiramate in the treatment of obesity. Lancet. July 9, 2011;378(9786):125-126; author reply 126-127.

78. Mercer SL. ACS chemical neuroscience molecule spotlight on Qnexa. ACS Chem Neurosci. April 20, 2011;2(4):183-184.

79. Shah K, Villareal DT. Combination treatment to CONQUER obesity? Lancet. April 16, 2011;377(9774):1295-1297.

80. Qsymia [prescribing information]. Mountain view, CA: Vivus; 2012.

81. Aronne LJ, Peterson C, Troupin B, et al. Weight loss with V1-0521 (phentermine/controlled release topiramate) stops progression towards type 2 diabetes in obese non-diabetic subjects. Poster PO.22 presented at: 2010 Obesity Society meeting and the abstract included in Obesity Facts.

82. Ryan DH, Peterson C, Troupin B, et al. Weight loss at 6 months with V1-0521 (PEN/TPM combination) treatment. Paper presented at the 69th Annual Scientific Sessions of the American Diabetes Association, June 5, 2009.

83. VIVUS I. VIVUS Reports Topline Findings from FORTRESS. [media release on the Internet]. December 21, 2011. Available at http://ir.vivus. com/releasedetail.cfm?ReleaseID $=634920$.

84. Barter PJ, Caulfield M, Eriksson M, et al. Effects of torcetrapib in patients at high risk for coronary events. $N$ Engl J Med. November 22, 2007;357(21):2109-2122.

85. Nissen SE, Wolski K, Topol EJ. Effect of muraglitazar on death and major adverse cardiovascular events in patients with type 2 diabetes mellitus. JAMA. November 23, 2005;294(20):2581-2586.

86. Nissen SE, Wolski K. Rosiglitazone revisited: an updated meta-analysis of risk for myocardial infarction and cardiovascular mortality. Arch Intern Med. July 26, 2010;170(14):1191-1201.
Drug Design, Development and Therapy

\section{Publish your work in this journal}

Drug Design, Development and Therapy is an international, peerreviewed open-access journal that spans the spectrum of drug design and development through to clinical applications. Clinical outcomes, patient safety, and programs for the development and effective, safe, and sustained use of medicines are a feature of the journal, which

\section{Dovepress}

has also been accepted for indexing on PubMed Central. The manuscript management system is completely online and includes a very quick and fair peer-review system, which is all easy to use. Visit http://www.dovepress.com/testimonials.php to read real quotes from published authors. 